\title{
A Method for Composite Wing Box Optimization with Manufacturing Constraints
}

\author{
X.P. Zhong, P. Jin, Q. Han \\ School of Aeronautics \\ Northwestern Polytechnical University \\ Xi'an, China, 710072
}

\begin{abstract}
An optimization strategy is presented for composite wing box structure using genetic algorithm with manufacturing constraints. Firstly, on the basis of region division and key region defined, both fiber orientation angle and covered length of each ply are treated as design variables to optimize laminate thickness and stacking sequence simultaneously while maintaining laminate ply continuity. Secondly, a parallel genetic algorithm (GA) is adopted to accelerate optimization process. Finally, a composite wing box is used to demonstrate the effectiveness of the proposed method. The result shows that the optimization method can obtain optimum design with light weight which satisfies manufacturing constraints for large composite wing structure.
\end{abstract}

Keywords-composite wing box; manufacturing constraints; ply continuity; parallel genetic algorithm

\section{INTRODUCTION}

Advanced fiber-reinforced composites gain increasing interest and are growingly used in automotive, aerospace, and marine structures due to their high stiffness-to-weight and strength-to-weight ratios. Designs of laminate configurations of composite panels, including laminate thicknesses and stacking sequences, are of vital importance to achieve the required structure mechanical behaviors for specific sets of loading conditions.

For large composite wing structure, the panel is often divided into several smaller sub-regions to avoid overdesigning the wing structure due to different load level of each region. A common problem with the design of composite structure consist in that the laminate configurations between adjacent regions may vary from each other, i.e. different thickness and stacking sequence exist, causing incompatibilities in stacking sequence. The incompatibilities across panel design boundaries will bring manufacturing difficulties, increase costs and lead to structural integrity issues. Thus, stacking sequence blending design of laminate panels has received more and more attention.

Since the term blending was introduced by Kristinsdottir et al. to illustrate the ply continuity problem [1], many papers have contributed to the investigation of the composite structure blending models. Liu [2] and Toropov [3] developed and applied two measures of continuity in terms of material composition and stacking sequence between adjacent panels to obtain blended composite panel. Soremekun et al. [4] used DARWIN's sub-laminates and design variable zone features to design completely blended composite structures. Adams $[5,6]$ achieved a blended design using a guide based genetic algorithm and developed two blending models, inner and outer blending, to maintain the ply continuity between adjacent laminates. Campen [7] proposed two new blending definitions, generalized blending and relaxed generalized blending.

In this paper, an optimization method based on parallel genetic algorithm that can make laminate thickness and stacking sequence be optimized simultaneously is presented to find the global optima. This method divides the panel to be optimized into individual regions for sufficient reduction in weight. An indicator that identifies the key region (thickest region) from which plies originates and can cover a number of adjacent regions is determined. All plies start from the key region and a ply can be stopped between adjacent regions if the required strengths and stiffness are satisfied. Once the ply is dropped, it is not allowed to be added back to the latter regions. For a single ply, two different indicators are incorporated in the optimization formulations for the design of composite panels. The first indicator uses an integer $\theta$ to determine its ply angle. $\theta=1,2,3$ and 4 corresponds to the fiber angle of $-45,0,45$ and 90 degrees. The second indicator uses an integer $L$ to determine how many regions a ply occupies, e.g. $L=2$ represents the ply continues through the first two regions, $L=0$ implies that the ply does not exist.

\section{Optimization Model of A Wing Box}

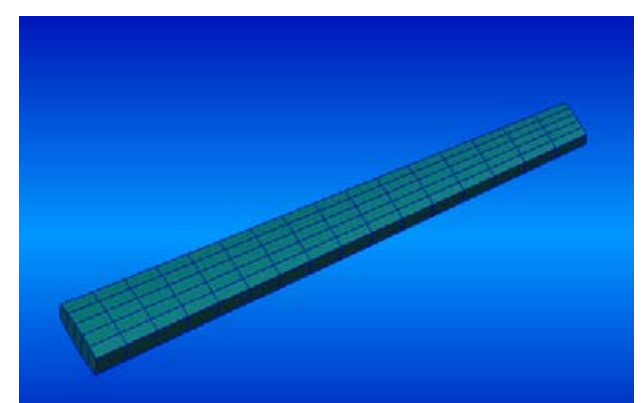

FIGURE I. FINITE ELEMENT MODEL OF WING BOX.

A composite wing box which is the main load-carrying component is to be optimized. Figure 1 shows the finite element model of the wing box. The elements can be grouped into several regions along the span wise direction. In each region, the properties of the elements are identical, i.e. the same thickness and lay-up. The optimization model for the composite wing is stated as follows. 


\section{A. Objective Function}

The objective is the mass of the composite wing.

$$
\min W=W_{0}+\sum_{i=1}^{n} \rho h S_{i}
$$

Here $W_{0}$ is the weight that is kept constant during the optimization process. $\rho$ and $h$ are referred to as the material density and ply thickness, respectively. $S_{i}$ stands for the total area of ply $i$, and $n$ denotes the number of plies.

\section{B. Design Variables}

The design variables in the optimization formulation are the two different indicators of each ply, $\theta_{i}$ and $L_{i}$. $\theta_{i}$ is the ply angle, and $L_{i}$ defines the regions covered by the ply. In equation (1), $S_{i}$ is related to $L_{i}$.

\section{Constraints}

The following subsections describe the constraints imposed on the optimization of the composite wing.

1) Strength constraints: Strength constraints are introduced to limit the magnitude of strains in tension, compression and shear undertaken by the laminate. Design strain levels of $4000 \mu \varepsilon$ in both tension and compression and $4000 \mu \varepsilon$ in shear are imposed.

2) Stiffness Constraints: Wing tip displacement constraint and torsion angle constraint are taken in account to keep the bending and torsion stiffness of the wing to prevent the aero loads be deteriorated dramatically.

\section{3) Manufacturing constraints:}

a. The lay-up is balanced, i.e. the number of $45^{\circ}$ plies and $45^{\circ}$ plies is identical in each region.

b. Due to the damage tolerance requirements, the outer plies of the skin laminate should always contain at least one set of $\pm 45^{\circ}$ plies.

c. The number of plies in any one direction stacked consecutively is limited to 4 .

4) Bucking constraints: Bucking constraints are considered as Reference 8.

\section{OPTIMIZATION ALgORITHM}

It has been recognized that optimal design of composite structures is a global optimization problem with multiple local optima and a complex design space, and the GA is an ideal tool for a discrete design problem and a multiple local optima problem.

The fiber orientation angles are often limited to $0^{\circ}, \pm 45^{\circ}$ and $90^{\circ}$ to ease manufacturing effort and reduce cost. In this paper, each individual representing a single design is encoded into a digital string. The $0^{\circ}$ ply is encoded into the digit 1 , the $45^{\circ}$ ply the digit 2 , the $-45^{\circ}$ ply the digit 3 , and the $90^{\circ}$ ply the digit 4 . For example, a design $[0 / 45 / 0 /-45 / 90]$ is coded as [1 2 $\left.\begin{array}{lll}1 & 3 & 4\end{array}\right]$. The population is composed of a set of such digit strings appended by the substring representing the length covered by each ply. The elitist selection scheme is incorporated to evolve population in the algorithm. Promising individuals from an extended population consisted of parent and offspring population are selected as the new parent population in next generation. And mating selection from the parent population to recombination is conducted by using a tournament strategy. Thus well balance can be reached between the survival pressure of each individual and diversity maintaining of the population during the optimization process.

The master-slave parallel GA [8] is adopted to decrease optimization time. The master-slave GA system is divided into one master process and several slave processes. The master process controls the whole population and carries on the operations of selection, crossover, and mutation. The slave processes receive the subpopulation sent by the master process and evaluate their fitness functions, and then send the results back to the master process. Information sending and receiving are the key points in the parallel GA. Functions MPI_Send and MPI Recv in the MPI lib [9] are used to pass information between the master and slave processes. The frame for the master-slave parallel GA based on MPI is shown in Figure2.

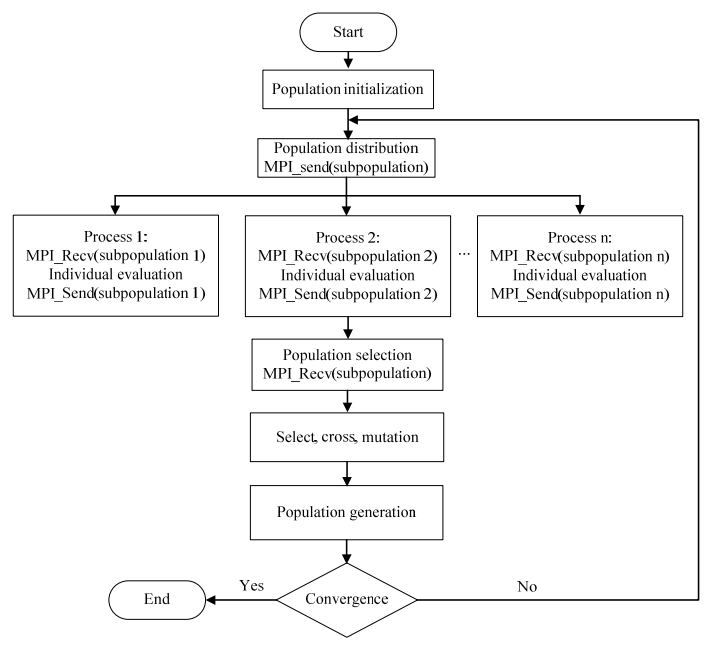

FIGURE II. MASTER-SLAVE PARALLEL GA BASED ON MPI

\section{OptimizATION RESUlts}

The objective of this optimization is to find the lightest weight of the composite wing box in figure 1. The behavior constraints, global stiffness constraints, local strength constraints, buckling constraints, and composite manufacturing constraints are imposed. The top and the bottom skin layer are the targeted design panels. The wing box model is divided into 8 regions as in Figure 3, and Figure 4 details the wing section. For simplicity, the top and the bottom skin of the wing box in the same region have the same stacking sequence in this optimization problem. The possible ply orientations for the design panels are $0^{\circ}, \pm 45^{\circ}$ and $90^{\circ}$, while all other panels are fixed to the design of $\left[04_{4} / 45_{4} / 0_{4} /-45_{4} / 90_{4}\right]_{S}$. Table 2 shows the material properties of T300/N5208, where $\rho$ is the density and $t$ is the thickness of a ply. 


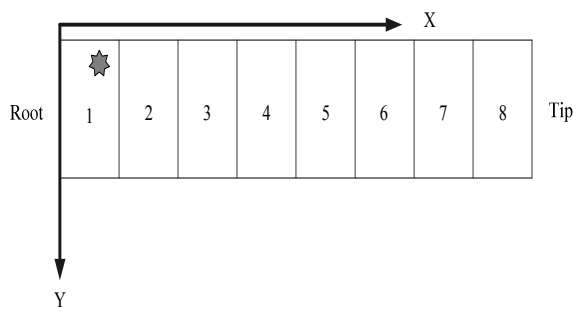

FIGURE III. REGION DIVISION ALONG SPAN WISE OF WING BOX.

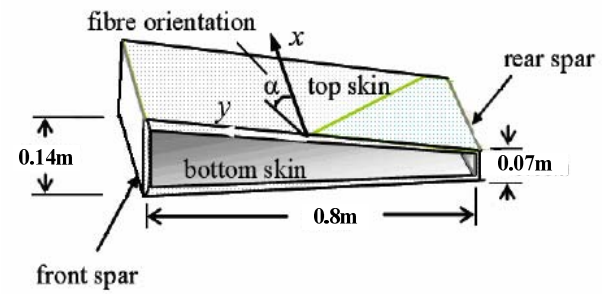

FIGURE IV. GEOMETRY OF WING CROSS SECTION.

TABLE I. MATERIAL PROPERTIES OF T300/N5208.

\begin{tabular}{cccccc}
\hline \hline E11 [GPa & E22 [GPa & $\mu_{12}$ & $\mathrm{G}[\mathrm{GPa}]$ & $\rho[\mathrm{kg} / \mathrm{m} 3]$ & $\mathrm{t}[\mathrm{mm}]$ \\
\hline 127.56 & 13.03 & 0.3 & 6.41 & 1577.76 & 0.127 \\
\hline \hline
\end{tabular}

The master-slave parallel GA presented above is employed to solve the wing box optimization problem. It is supposed that the initial top and bottom skins are both comprised of 100 plies. The stacking sequence for each panel is symmetric about its mid-plane. The running parameters of GA code are as follows: the population size is 400 , crossover probability is 0.9 , and mutation probability is 0.05 . The maximum generation is set to 400 .

Table 2 details the optimal design of the composite skin obtained by this optimization method. Results show that the wing root (the key region) is the thickest region, and some plies are dropped off in a latter thinner region. The design meets the manufacturing requirements. Therefore, for such large composite wing box structure an optimal blended design is found using the method proposed in this paper.

TABLE II. STACKING SEQUENCE OF UPPER SKIN REGIONS.

\begin{tabular}{ccc}
\hline Region & Stacking sequences & $\begin{array}{c}\text { Number } \\
\text { of plies }\end{array}$ \\
\hline 1 & {$\left[45 /-45 / 0_{2} / 45 / 90 / 45 / 0_{4} / 45_{2} / 0_{2} /-45 / 90 /-45 / 0_{3} / 45 / 0_{4} /-45_{3} / 0\right]_{\mathrm{s}}$} & 60 \\
2 & {$\left[45 /-45 / 0_{2} / 45 / 90 / 45 / 0_{4} / 45 / 0_{2} /-45_{2} / 0_{3} / 45 / 0_{2} /-45_{2}\right]_{\mathrm{s}}$} & 48 \\
3 & {$\left[45 /-45 / 0_{2} / 90 / 45 / 0_{4} / 45 / 0_{2} /-45_{2} / 0_{4}\right]_{\mathrm{s}}$} & 38 \\
4 & {$\left[45 /-45 / 0_{2} / 90 / 0_{3} / 45 / 0_{2} /-45 / 0_{3}\right]_{\mathrm{s}}$} & 30 \\
5 & {$\left[45 /-45 / 0 / 90 / 0_{3} / 45 / 0_{2} /-45 / 0_{3}\right]_{\mathrm{s}}$} & 28 \\
6 & {$\left[45 /-45 / 90 / 0_{3} / 45 / 0_{2} /-45 / 0_{3}\right]_{\mathrm{s}}$} & 26 \\
7 & {$\left[45 /-45 / 0_{2} / 45 / 0_{2} /-45 / 0_{3}\right]_{\mathrm{s}}$} & 22 \\
8 & {$\left[45 /-45 / 0_{2} / 45 / 0 /-45 / 0\right]_{\mathrm{s}}$} & 16 \\
\hline
\end{tabular}

\section{CONClusions}

Composite structure is often divided into multiple regions, each of which is optimized ignoring ply continuity in conventional multi-level optimization method. Mismatches between adjacent regions do inevitably occur in the obtained optimum. An optimization strategy is proposed for large composite structure using GA with manufacturing constraints by treating fiber orientation angle and covered length of each ply as design variables. Parallel master-slave GA based on MPI is used to improve the optimization efficiency. It is readily to get a blended design by considering manufacturability such as ply continuity in the proposed method. A composite wing box structure is optimized to demonstrate the effectiveness of this method. The optimal results show that a blended light weight design can be obtained using the method proposed in this paper.

\section{ACKNOWLEDGEMENT}

This study was supported by National Natural Science Foundation of China (No.11402204).

\section{REFERENCES}

[1] B.P. Kristinsdottir, Z.B. Zabinsky, M.E. Tuttle, S. Neogi, Optimal design of large composite panels with varying loads, Composite Structures. 51 (2001) 93-102.

[2] B. Liu, R.T. Haftka, Composite wing structural design optimization with continuity constraints. In: Proceedings of the 42nd AIAA/ASME/ASCE/AHA/ACS structures, structural dynamics and material conference (2001).

[3] Toropov, V.V., Jones, R., Willment, T., Weight and manufacturability optimization of composite aircraft components based on a genetic algorithm. In: Proceedings of 6th World Congress of SMO, Brazil, (2005).

[4] G.A. Soremekun, Z. Gurdal, C. Kassapoglou, Stacking sequence blending of multiple composite laminates using genetic algorithm, Composite Structures. 56 (2002) 53-62.

[5] D.B. Adams, L.T. Watson, Z. Gurdal, C.M Anderson-Cook, Genetic algorithm optimization and blending of composite laminates by locally reducing laminate thickness, Advances in Engineering Software. 35 (2007) 35-45.

[6] Seresta, O, Gurdal, Z., Adams D.B., Watson, L.T., Optimal design of composite wing structures with blended laminates, Composites: Part B. 38 (2007) 469-480.

[7] J.M. Van Campen, O. Seresta, M.M. Abdalla, Z. Gürdal, General blending definition for stacking sequence design of composite laminate structures. In: Proceedings of the 49th AIAA/ASME/ASCE/AHS/ASC Structures, Structural Dynamics and Materials Conference, Schaumburg, IL, USA,(2008).

[8] P. Jin, B. F. Song, and X. P. Zhong, Structure optimization of large composite wing with parallel genetic algorithm, Jornal of Aircraft. 48 (2011) 2145-2148.

[9] M.T. McMahon, L.T. Watson, A distributed genetic algorithm with migration for the design of composite laminate structures, Parallel Algorithms Appl. 14 (2000) 329-62. 